\title{
Organic Acid Metabolism Disorder
}

National Cancer Institute

\section{Source}

National Cancer Institute. Organic Acid Metabolism Disorder. NCI Thesaurus. Code C101334.

An inherited disorder that affects the metabolism of any acidic compound containing carbon in a covalent linkage. 